Chapter 27

\title{
Rigid Fixation of Intraoral Vertico-Sagittal Ramus Osteotomy for Mandibular Prognathism
}

\author{
Kazuma Fujimura and Kazuhisa Bessho \\ Additional information is available at the end of the chapter
}

http://dx.doi.org/10.5772/53303

\section{Introduction}

The standard surgical treatment for mandibular prognathism is sagittal split ramus osteotomy (SSRO) if the proximal and distal segments of the ramus require fixing with screws or metal plates. In this procedure, however, it is frequently difficult to avoid neurosensory disturbance (NSD) of the inferior alveolar nerve (IAN) when the posterior margin of the ramus curves inward or when the ramus is thin (Fig 1A,B).

This report describes a new alternative procedure, intraoral vertico-sagittal ramus osteotomy (IVSRO) reported by Choung in 1992. [1] It is a modification of SSRO and intraoral vertical ramus osteotomy (IVRO). It is supposed that IVSRO is more suitable for, mandibles with a ' $\mathrm{V}$ ' shape seen in adult Asians as compared to mandibles of Caucasians who have ' $U$ ' shaped mandibles. One of the main advantages of IVSRO is that it avoids IAN damage, because the ramus can be split parallel to the original sagittal plane posterior to the point between the mandibular canal and the lateral cortical bone plate immediately in front of the antilingular prominence. In this method the anterior border of the proximal segment is partially removed at the beginning of the osteotomy procedure as described by Kitajima et al. in 1989. [2] Another advantage of IVSRO is that the area in which screws can be inserted is relatively large; the subcoronoid area on the distal segment and subcondylar area on the proximal segment are engaged. These segments can be fixed in these areas with bicortical bone screws, without a cheek incision (Fig 1AC). This chapter introduces this procedure and the technique of rigid fixation of IVSRO for treatment of mandibular prognathism. 


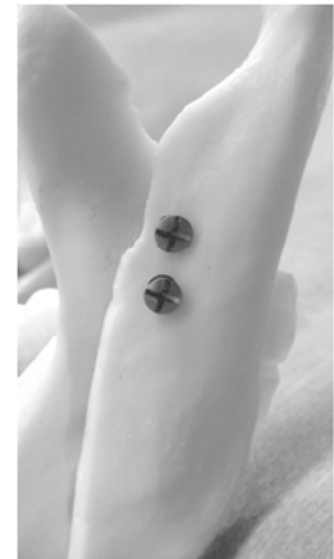

(a)

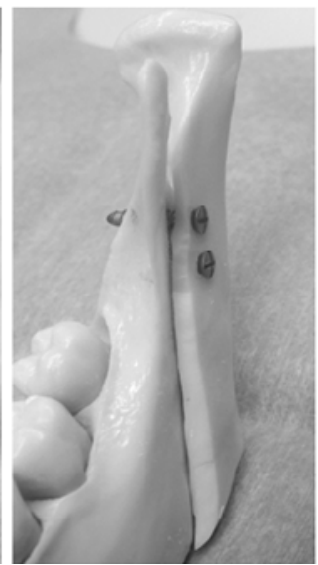

(b)

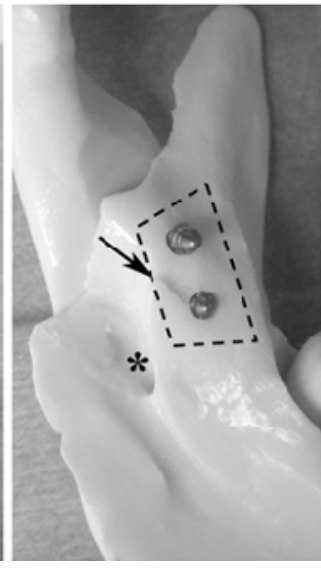

(c)

Figure 1. (a) Rigid fixation of intraoral vertico-sagittal ramus osteotomy using a mandibular model. Left mandibular ramus lateral view showing bone overlap and bicortical screw engagement. Screws can be inserted into the subcoronoid area on the distal segment in the subcondylar area on the proximal segment; (b) Left mandibular ramus frontal view showing bicortical engagement of screws; (c) Left mandibular ramus medial view showing relatively large area for screw insertion (dashed rectangular area). Arrow indicates lingula of mandible. Asterisk indicates mandibular foramen.

\section{Technique}

Osteotomy of the ramus via IVSRO is a modified version of the 'straight IVSRO'. [1] Briefly, the lateral aspect of the ramus is exposed from the sigmoid notch to the antegonial notch. To avoid damaging the IAN and the maxillary artery, the medial aspect of the ramus may also be exposed carefully from the sigmoid notch area to the lingula and the posterior border of the ramus, as in SSRO. [3] To avoid a fracture or bad split, the full thickness of the sigmoid notch is cut with a fissure bur, reciprocating saw, oscillating saw or ultrasonic surgical device inferiorly along the planned decortication line until the bone marrow is exposed. This process, full-thickness cutting of the sigmoid notch, is the most important and most technically difficult step of the IVSRO procedure. A wedge-shaped decortication of the lateral aspect of the ramus from the sigmoid notch to the antegonial notch is performed using a flat-top, cylindrical fissure bur parallel to the original sagittal plane until the bone marrow is exposed. [4] A bone spatula and an osteotome are used for vertical osteotomy along almost the entire sagittal plane to the medial posterior border of the ramus. The distal segment is then repositioned posteriorly, and intermaxillary fixation (IMF) is performed. The inner aspect of the decorticated distal segment is spontaneously overlapped on the proximal segment. The subcoronoid area and the subcondylar area in each segment also overlap. These segments can be fixed using bicortical bone screws. A $90^{\circ}$ screw driver system (eg, angled drilling system and insertion screws with a $12 \mathrm{~mm}$ screw length) is used with an intraorally (Fig $1 \mathrm{~A}-\mathrm{C}$ ). 
When the two segments are fixed rigidly, IMF is usually not required after surgery. However, a favorable outcome is usually obtained with IMF for about 3 days to prevent postoperative bleeding and to aid in wound healing. To stabilize the occlusion postoperatively, intermaxillary elastics are applied for about 2-3 months after release of IMF.

\section{Discussion}

The main advantage of rigid fixation IVSRO over SSRO in treating prognathism, when the posterior margin of the ramus curves inward or the ramus is thin, may be the decreased risk of postoperative NSD. The incidence of long-term NSD of the lower lip and chin in IVSRO is $0 \%$ to $6 \%[1,5,6]$ compared with $39 \%$ to $85 \%$ [7-11] for SSRO. Although the osteotomy plane is between the mandibular canal and the lateral cortical plate of the ramus as in SSRO, damage to the IAN can be avoided because the osteotomy is performed from a point in front of the foramen between the mandibular canal and the immediately medial lateral cortical bone.[1, 2] making it possible to strip the lateral cortical bone from the bone marrow. Although a low incidence of NSD is also observed with IVRO, [10,12] rigid fixation with screws or bone plates has several disadvantages, including technical difficulty $[10,13]$ and rotation of the condyle to the laterally.[1] IVSRO is distinguished by flat and larger contact areas of segments and more favorable healing of the medulla to the cortex than the cortex-to-cortex healing of IVRO. [1] In $\mathrm{SSRO}$, the excess overlap of the anterior edge of the proximal segment must be removed to fit the two segments and/or prevent distal rotation of the proximal segment. [14] In IVSRO, there is no excess overlap of the proximal segment. It is easy to check the position of the distal segment after osteotomy because the anterior area of the proximal segment is removed beforehand; hence, the subcoronoid area of the distal segment and the subcondylar area of the proximal segment can be used for insertion of screws. The area available for screw insertion is relatively large and the ends of the inserted screws may be viewed at the medial aspect of the distal segment because, at the internal oblique ridge, the bone thickness of this subcoronoid area in the distal segment is relatively thin compared with the retromolar areas as in SSRO. Therefore, in many patients, a $90^{\circ}$ angle screwdriver system with $12-\mathrm{mm}$ length screws can be used without drilling through a trocar inserted through the skin (Fig 2 A-C).

\section{Conclusion}

When planning rigid fixation using IVSRO, the following conditions are preferable: Mandibular setback (about $\geqq 5 \mathrm{~mm}$ ) and counterclockwise rotation. Because this osteotomy procedure has a large contact area between the proximal and distal segments, compared with IVRO, the segments are usually fixed with screws in only the setback side for horizontal rotation for mandibular asymmetry (Fig 2C). Additional studies including the development of osteotomy instruments and drilling systems to simplify the surgical procedure of IVSRO are needed to validate the advantages of this procedure. 


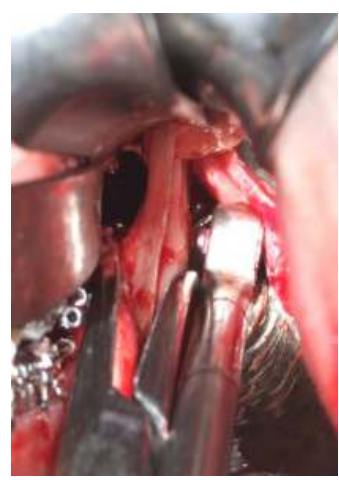

(a)

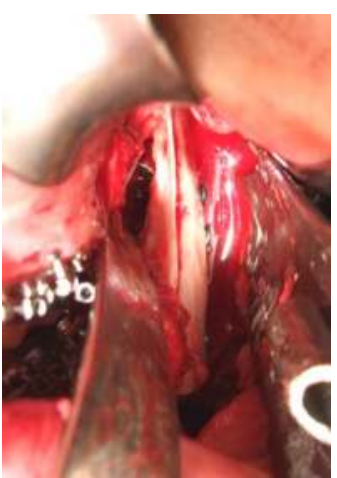

(b)

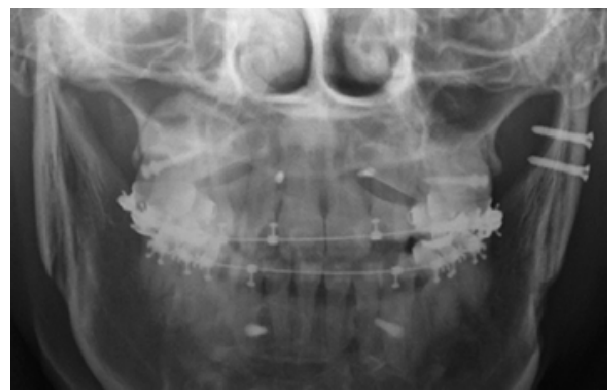

(c)

Figure 2. (a) Intraoral vertico-sagittal ramus osteotomy of the left ramus (frontal view). A $90^{\circ}$ angled screwdriver drilling system and insertion screws, 12-mm in length; (b) Two 12-mm screws $2.4 \mathrm{~mm}$ in diameter inserted intraorally.

\section{Author details}

Kazuma Fujimura and Kazuhisa Bessho

*Address all correspondence to: fujimura@kuhp.kyotou.ac.jp

Department of Oral and Maxillofacial Surgery, Graduate School of Medicine, Kyoto University, Kyoto, Japan

\section{References}

[1] Choung PH: A new osteotomy for the correction of mandibular prognathism: Techniques and rationale of the intraoral verticosagittal ramus osteotomy.J Craniomaxillofac Surg 20:153, 1992 
[2] Kitajima T, Handa $Y$, Naitoh K: A modification of the sagittal splitting technique ensuring that the osteotomy split lies immediately medial to the lateral cortex. J Craniomaxillofac Surg 17:53, 1989

[3] Fujimura K, Segami N, Kobayashi S: Anatomical study of the complications of intraoral vertico-sagittal ramus osteotomy. J Oral Maxillofac Surg 64:384, 2006

[4] Fujimura K, Segami N, Sato J, et al: Advantages of intraoral verticosagittal ramus osteotomy in skeletofacial deformity patients with temporomandibular joint disorders. J Oral Maxillofac Surg 62:1246, 2004

[5] Lima Júnior SM, Granato R, Marin C, et al: Analysis of 40 cases of intraoral verticosagittal ramus osteotomies to treat dentofacial deformities. J Oral Maxillofac Surg 67:1840, 2009

[6] Hashemi HM: Evaluation of intraoral verticosagittal ramus osteotomy for correction of mandibular prognathism: A 10-year study. J Oral Maxillofac Surg 66:509, 2008

[7] Walter JM Jr, Gregg JM: Analysis of postsurgical neurologic alteration in the trigeminal nerve. J Oral Surg 37:410, 1979

[8] MacIntosh RB: Experience with the sagittal osteotomy of the mandibular ramus: A 13year review. J Maxillofac Surg 9:151, 1981

[9] Nishioka GJ, Zysset MK, Van Sickels JE: Neurosensory disturbance with rigid fixation of the bilateral sagittal split osteotomy. J Oral Maxillofac Surg 45:20, 1987

[10] Hall HD: Mandibular prognathism, in Bell WH (ed): Modern Practice in Orthognathic and Reconstructive Surgery. Philadelphia, PA, WB Saunders, 1992, p 2111

[11] Westermark A, Bystedt H, von Konow L: Inferior alveolar nerve function after mandibular osteotomies. Br J Oral Maxillofac Surg 36:425, 1998

[12] van Merkesteyn JP, Groot RH, Van Leeuwaarden R, et al: Intra-operative complications in sagittal and vertical ramus osteotomies. Int J Oral Maxillofac Surg 16:665, 1987

[13] Ghali GE, Sikes JW Jr: Intraoral vertical ramus osteotomy as the preferred treatment for mandibular prognathism. J Oral Maxillofac Surg 58:313, 2000

[14] Sickels JEV, Jeter TS, Aragon SB: Orthognathic surgery, in Bell WH (ed): Modern Practice in Orthognathic and Reconstructive Surgery. Philadelphia, PA, WB Saunders, 1992, p 1980 
